\title{
Synthesis, characterization and biological applications of biosilica based composites
}

\author{
P. Supriya Prasad ${ }^{a}$, T. Gomathi ${ }^{b}$, P.N. Sudha ${ }^{b}$, M. Deepa ${ }^{a^{*}}$ \\ ${ }^{a} P G$ and Research Department of Chemistry, Muthurangam Govt. Arts College, Affiliated to \\ Thiruvalluvar University, Vellore, Tamil Nadu, India \\ ${ }^{b} P G$ and Research Department of Chemistry, D.K.M. College for Women, Affiliated to \\ Thiruvalluvar University, Vellore, Tamil Nadu, India \\ (Corresponding author email: deeparam79@gmail.com)
}

\begin{abstract}
Agricultural wastes like sugarcane bagasse, rice husk, wheat husk, rice hull are the cheapest sources of biosilica (BS). In this study, sugarcane bagasse was used to extract biosilica by chemical treatment and combined with silk fibroin (SF), Polyurethane Foam (PUF) and $\mathrm{TiO}_{2}$ to prepare a novel biocomposites $B S / S F / P U F$ and BS/SF/PUF/TiO 2 . The prepared biocomposites were analyzed using FT-IR and SEM analysis. The presence of various functional groups and the formation of biocomposites were confirmed by the FT-IR studies. The SEM analysis displayed rough surface morphology of the biocomposites. The antioxidant properties were studied using the DPPH assay. The biocomposites exhibited excellent antioxidant properties. The antimicrobial activities of the biocomposites were studied against three bacterial (Bacillus sp., Klebsiella sp. and Proteus sp.) and three fungal strains (Rhizopus sp., Aspergillus niger and Candida sp.). The results revealed that the prepared biocomposites were active against the selected bacterial and fungal species.
\end{abstract}

Keywords: Biosilica, Silk fibroin, polyurethane foam, antioxidant, antimicrobial.

\section{Introduction}

Agricultural systems are dependable methods for increasing human food production by utilising natural resources. Sugarcane bagasse is one of the main food plants that were used. It is the cheapest, attractive alternative sources of biosilica (BS) that containing high silica content. Silicon $(\mathrm{Si})$ is an important macroelement in plant life cycles. It is the $8^{\text {th }}$ common element next to oxygen and second most prevalent element found in soil [1]. The availability of silicon in the soil influences silica concentration; sugarcane roots play a key role in absorbing silicic acid from the soil and delivering it to the shoots, where it is deposited as amorphous silica [2]. Therefore the highly reactive biosilica was extracted in this present work and used for the preparation of biocomposites. Generally, thermal and chemical methods were used to extract biosilica. Thermal method involves the direct combustion of biomass at very high temperature so that the carbonaceous matter can be eliminated. The chemical method involves the treatment of biomass with sodium hydroxide for the precipitation of sodium silicate, which then is treated with acid at a particular $\mathrm{pH}$. This method is can be referred to as the sol-gel method [3]. In this study, biosilica was extracted from sugarcane bagasse by the chemical method. Extracted biosilica was combined with silk fibroin, polyurethane foam and $\mathrm{TiO}_{2}$ to prepare novel BS/SF/PUF and $\mathrm{BS} / \mathrm{SF} / \mathrm{PUF} / \mathrm{TiO}{ }_{2}$ biocomposites. 
Silk Fibroin (SF) is a natural biopolymer extracted from the silk worm Bombyx mori $s p$., has been recognized as a potentially useful biomaterial due to its exquisite perdurable biodegradability, chemical reactivity, mechanical properties, minimal flammability and distinguished biocompatibility [4]. The silk obtained from Bombyx mori is of premium quality and is used till date for its superior properties like robustness, lustre, resilience, ability to conform to the surface of molds, ease of manipulation and ability to bind with chemical dyes. It is also recognized for its applications in the field of medicine [5].

Polyurethanes (PUF) are among the most extensively utilised synthetic biomedical polymers due to their excellent biocompatibility and simplicity of modification [6]. Because of its low cost, strong photocatalytic efficacy, high chemical stability, and biocompatibility, titanium dioxide $\left(\mathrm{TiO}_{2}\right)$ has sparked a lot of interest in the environmental and energy industries [7]. $\mathrm{TiO}_{2}$ has antibacterial properties because it can mediate photocatalysis with enough energy to form active oxygen species (ROS) such $\mathrm{OH}, \mathrm{H}_{2} \mathrm{O}_{2}$, and $\mathrm{O}_{2}^{-}$, which are important in the destruction of microbial cells [8]. The aim of this study is to extract biosilica from sugarcane bagasse by chemical method. To prepare novel biocomposites using BS, SF, PUF and $\mathrm{TiO}_{2}$ and to characterize the biocomposites using FT-IR and SEM, and study the free radical scavenging activity and antimicrobial activity.

\section{Materials and Methods}

The materials chiefly used in the present work includes biosilica extracted from sugarcane bagasse, obtained from a local shop in Vellore. Silk acquired from the cocoons of Bombyx mori from a sericulture farm in Vaniyambadi, Tamilnadu India. Polyurethane was procured from Star Foams, Ranipet. All the chemicals used were of analytical grade without further purification.

\section{Preparation of Biosilica from sugarcane bagasse}

Initially, the sugarcane bagasse was washed with water and dried under sunlight for 24 hours to remove moisture. Then, the dried bagasse was incinerated in a muffle furnace at $600^{\circ} \mathrm{C}$ for 6 hours to obtain sugarcane bagasse ash. The ash was then treated with $1 \mathrm{M}$ solution of $\mathrm{HCl}$ and stirred for 2 hours. It was filtered using Whatmann filter paper. The residue was dried for 24 hours. Then, the residue was treated with $3 \mathrm{M} \mathrm{NaOH}$ solution, stirred for 3 hours at $40^{\circ} \mathrm{C}$. It was filtered again and the residue was washed with double distilled water. The solution was left undisturbed to attain room temperature. The $\mathrm{pH}$ of the solution was adjusted to 8 by the addition of $2 \mathrm{M} \mathrm{H}_{2} \mathrm{SO}_{4}$. At this point, silica gel is obtained. It is then heated in the muffle furnace at $700^{\circ} \mathrm{C}$ for 6 hours. Thus, white powder of biosilica is obtained.

\section{Preparation of BS/SF/PUF (1:1:1) composite}

The biocomposite BS/SF/PUF was prepared by combining about $1 \mathrm{~g}$ of biosilica and $1 \mathrm{~g}$ of finely chopped silk were added to $1 \mathrm{~g}$ of polyurethane foam (dissolved in $100 \mathrm{ml}$ of formic acid). The mixture was stirred for about an hour on a magnetic stirrer. Then, the mixture was left behind for 24 hours to remove the air bubbles, the prepared composite was poured in a petridish and was allowed to dry. Thus, the films of the composite $\mathrm{BS} / \mathrm{SF} / \mathrm{PUF} / \mathrm{TiO}_{2}(1: 1: 1: 1)$ were prepared.

\section{Preparation of BS/SF/PUF/TiO 2 (1:1:1:1) composite}

The novel biocomposite $\mathrm{BS} / \mathrm{SF} / \mathrm{PUF} / \mathrm{TiO}_{2}$ was prepared by initially combining $1 \mathrm{~g}$ of biosilica and $1 \mathrm{~g}$ of finely chopped silk were added to $1 \mathrm{~g}$ of polyurethane foam (dissolved in $100 \mathrm{ml}$ of formic acid). The mixture was stirred for about an hour on a magnetic stirrer. Then, $1 \mathrm{~g}$ of $\mathrm{TiO}_{2}$ was added and stirred well. Once the stirring was completed, the mixture was left 
behind for 24 hours for the removal of air bubbles. Then, the prepared composite was poured in a petridish and was allowed to dry. Thus, the films of the composite $\mathrm{BS} / \mathrm{SF} / \mathrm{PUF} / \mathrm{TiO}_{2}$ $(1: 1: 1: 1)$ were prepared.

Thus, the biocomposites synthesized were then characterized and were tested for their antioxidant activity and antimicrobial activity.

\section{Sample Characterization}

The FT-IR spectra of the synthesized BS/SF/ PUF and BS/SF/PUF/TiO 2 biocomposites were recorded in the wave number range of $400-4000 \mathrm{~cm}^{-1}$ by Perkin Elmer 200 FTIR spectrophotometer with the resolution of $2 \mathrm{~cm}^{-1}$. The surface morphology of the biocomposites was studied by using a Scanning Electron Microscope (SEM) (JM 6701F 6701).

\section{Antioxidant Assay}

The antioxidant studies were conducted using the DPPH free radical scavenging assay. One of the prime methods of analyzing the free radical scavenging activity is the DPPH free radical scavenging activity. The assay was executed by mixing the prepared biocomposites $(20-120 \mu \mathrm{g} / \mathrm{ml})$ with $4 \mathrm{ml}$ of DPPH $(0.004 \%$ methanolic solution of DPPH). It was then incubated for half an hour at room temperature. After the completion of incubation, the radical scavenging potential of the biocomposites were investigated by calculating the decrease in absorbance of DPPH from $517 \mathrm{~nm}$. The control used was a blank solution of DPPH. The percentage of scavenging was calculated using the equation given below:

$$
\% \text { Scavenging Activity }=\left\{\left(\mathrm{A}_{\mathrm{C}}-\mathrm{A}_{\mathrm{S}}\right) / \mathrm{A}_{\mathrm{C}}\right\} \times 100
$$

where, Ac - absorbance of the control

As - absorbance of the solution containing the biocomposite

\section{Antimicrobial Activity}

The antimicrobial activity of the prepared biocomposites BS/SF/PUF and $\mathrm{BS} / \mathrm{SF} / \mathrm{PUF} / \mathrm{TiO}_{2}$ were tested against three bacterial and three fungal strains by the Agar Well Diffusion method with the help of the Muller Hinton Agar (MHA) medium. The bacterial strains used in the current work were Bacillus sp., (gram positive model) Klebsiella sp. and Proteus sp. (gram negative model) and the fungal strains used were Rhizopus sp., Aspergillus niger and Candida sp. Initially the microorganisms were inoculated on the MHA medium. A sterile spreader was used to spread it evenly. The MHA medium was allowed to congeal. A small quantity of the biocomposites $\mathrm{BS} / \mathrm{SF} / \mathrm{PUF}$ and $\mathrm{BS} / \mathrm{SF} / \mathrm{PUF} / \mathrm{TiO}_{2}$ prepared were placed on different cultured agar plates. For the diffusion of the biocomposites, the plates were allowed to stay undisturbed for one hour at room temperature. Before the initiation of the growth of the microorganisms, the plates were kept on different racks for 24 hours at $37^{\circ} \mathrm{C}$ for incubation. Both antibacterial and the antifungal activities of the prepared biocomposites were ascertained by estimating diameter of the zone of inhibition grown around the discs against the microorganisms using the measuring scale.

\section{Results and Discussion}

\section{Fourier Transform Infrared Analysis}

FTIR spectroscopy is used to characterise materials and to understand how changes in the chemical structure of the samples occur. FTIR research was used to investigate structural changes that occurred throughout the mixing process. The interactions between BS, SF, PUF, 
and $\mathrm{TiO}_{2}$ were determined using FTIR spectroscopy. The infrared spectra of BS, BS/SF/PUF and $\mathrm{BS} / \mathrm{SF} / \mathrm{PUF} / \mathrm{TiO}_{2}$ are given in figures $1-3$.

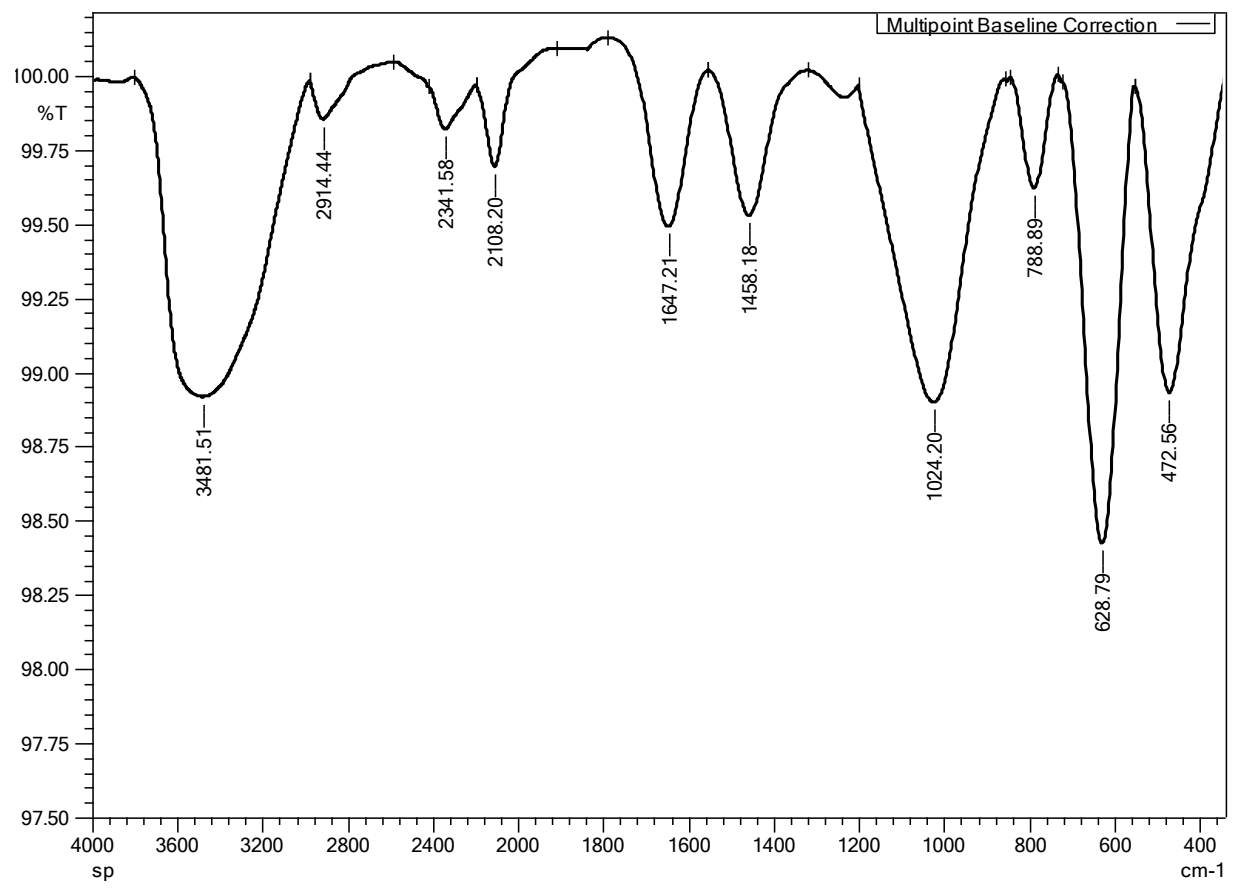

Fig.1: FT-IR spectrum of BS

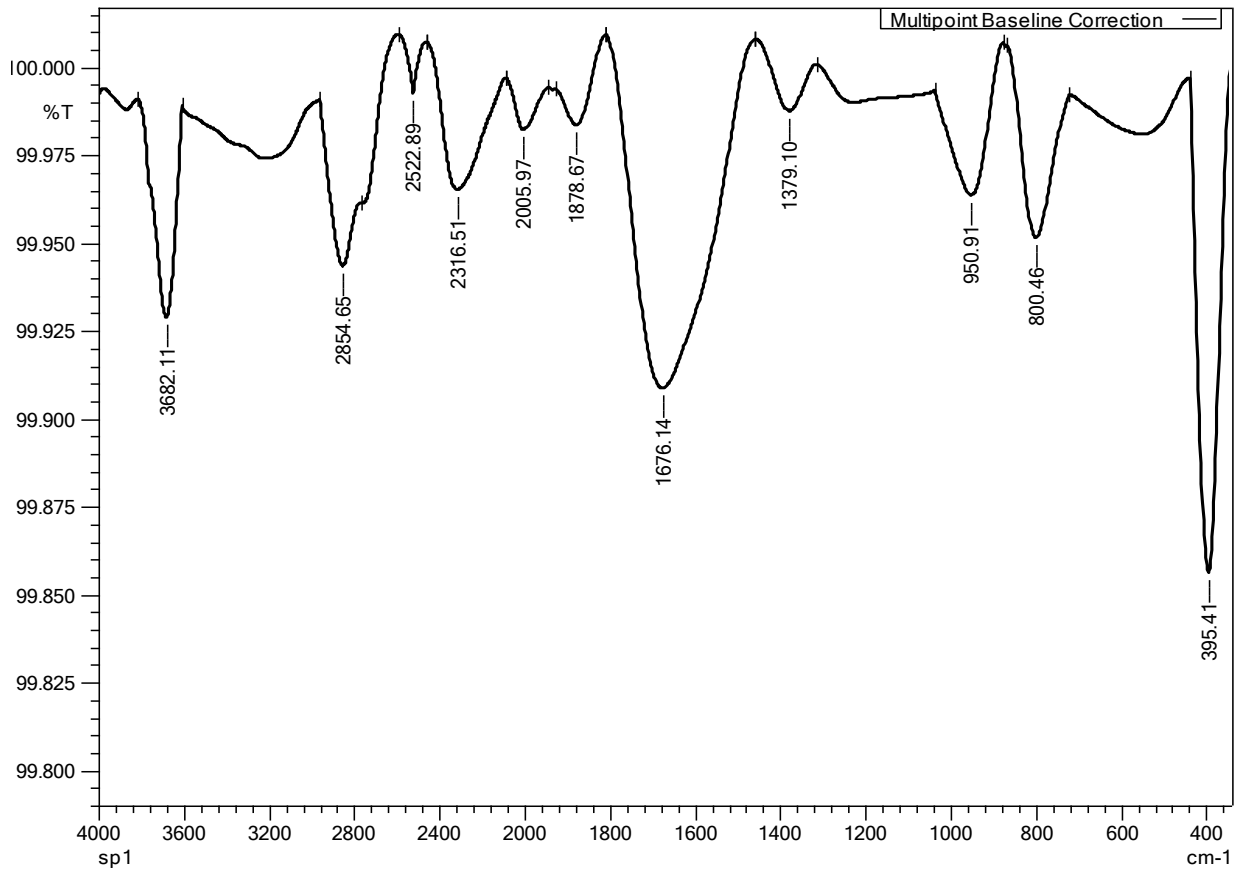

Fig 2: FT-IR spectrum of BS/SF/PUF (1:1:1) 


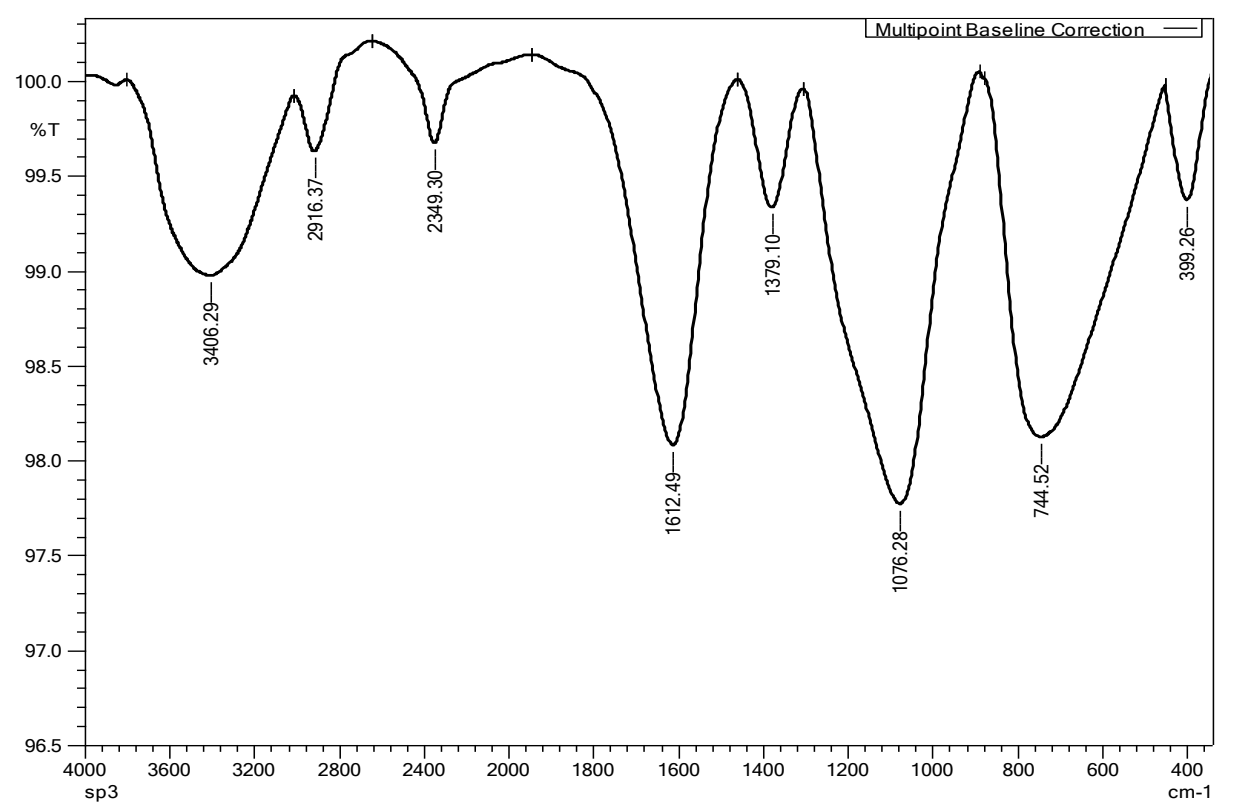

Fig 3: FT-IR spectrum of BS/SF/PUF/TiO 2 (1:1:1:1)

Table 1: FT-IR details of BS, BS/SF/PUF, BS/SF/PUF/TiO 2 biocomposites

\begin{tabular}{|c|c|c|l|}
\hline \multirow{3}{*}{ BS } & $\begin{array}{c}\text { Wavenumber }\left(\mathbf{c m}^{-\mathbf{1}} \mathbf{\text { BSF/PUF }}\right. \\
\text { biocomposite }\end{array}$ & $\begin{array}{c}\text { BS/SF/PUF/TiO } 2 \\
\text { biocomposite }\end{array}$ & \multirow{2}{*}{ Functional Group } \\
\hline 3481 & 3550 & 3406 & $\begin{array}{l}\text { OH and NH stretching } \\
\text { vibration }\end{array}$ \\
\hline 2916 & 2931 & 2916 & Asymmetric CH Stretching \\
\hline 1647 & 1714 & 1612 & C=O Stretching \\
\hline- & 1408 & 1379 & CH deformation \\
\hline 1024 & 1107 & 1076 & $\begin{array}{l}\text { Si-O-Si stretching and C-O } \\
\text { stretching }\end{array}$ \\
\hline 788 & 794 & - & Si-O stretching \\
\hline- & - & 744.52 & Ti-O stretching \\
\hline
\end{tabular}

The FT-IR spectra of BS, BS/SF/PUF (1:1:1) and BS/SF/PUF/TiO $2(1: 1: 1: 1)$ are shown in the figures 1,2 and 3 respectively. The band obtained between $3400 \mathrm{~cm}^{-1}$ and 3500 $\mathrm{cm}^{-1}$ is attributed to the $-\mathrm{NH}$ and $-\mathrm{OH}$ stretching vibrations and it proves the presence of intermolecular hydrogen bonding between the polymers. The peaks obtained at around 2900 $\mathrm{cm}^{-1}$ is due to $-\mathrm{CH}$ stretching vibrations present in the biocomposites [9]. The peak observed around $1020 \mathrm{~cm}^{-1}$ to $1100 \mathrm{~cm}^{-1}$ is associated with Si-O-Si stretching [10] and C-O stretching. The peak at $744.52 \mathrm{~cm}^{-1}$ is produced by the $\mathrm{Ti}-\mathrm{O}$ in $\mathrm{TiO}_{2}$, which confirms the presence of $\mathrm{TiO}_{2}$ in the $\mathrm{BS} / \mathrm{SF} / \mathrm{PUF} / \mathrm{TiO}_{2}$ biocomposite. The above band, exhibited even in bare $\mathrm{TiO}_{2}$, is noticed due to the vibrations of (Ti-O-Ti) stretching mode $[11,12]$. The peaks between 1600 $\mathrm{cm}^{-1}$ to $1700 \mathrm{~cm}^{-1}$ is because of the $\mathrm{C}=\mathrm{O}$ stretching of the amide group present in the silk [13]. The interactions between the polymers were observed by the distinctive variations in spectral bands when compared to pure samples [14,15]. When two or more substances are combined, physical blends vs chemical interactions are represented in changes in characteristic spectral bands, according to Yin et al. [16]. The hydrogen bonding formed between functional groups of silk fibroin, biosilica, polyurethane foam and titanium dioxide causes changes in the spectra as well as band shifting. 


\section{SEM Analysis}

Surface and structure of fibres, surface coating, and print in wood and paper are all studied using SEM. Chemical analysis of inorganic elements is possible, and it is possible to examine how they are distributed in the substance.

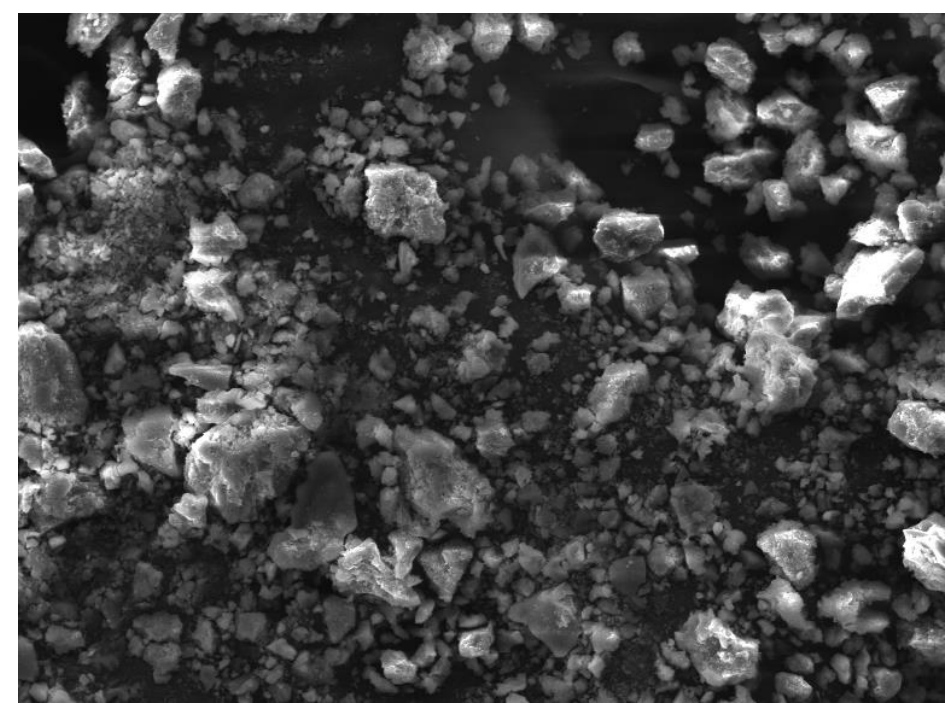

Fig 4: SEM of BS

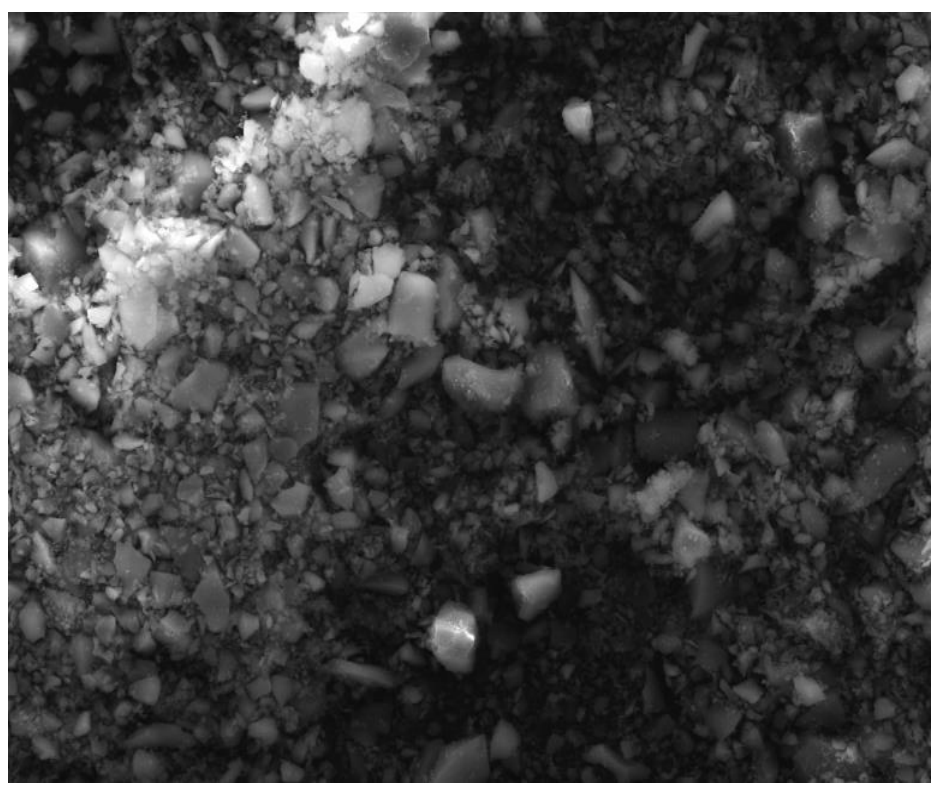

Fig 5: SEM of BS/SF/PUF (1:1:1) 


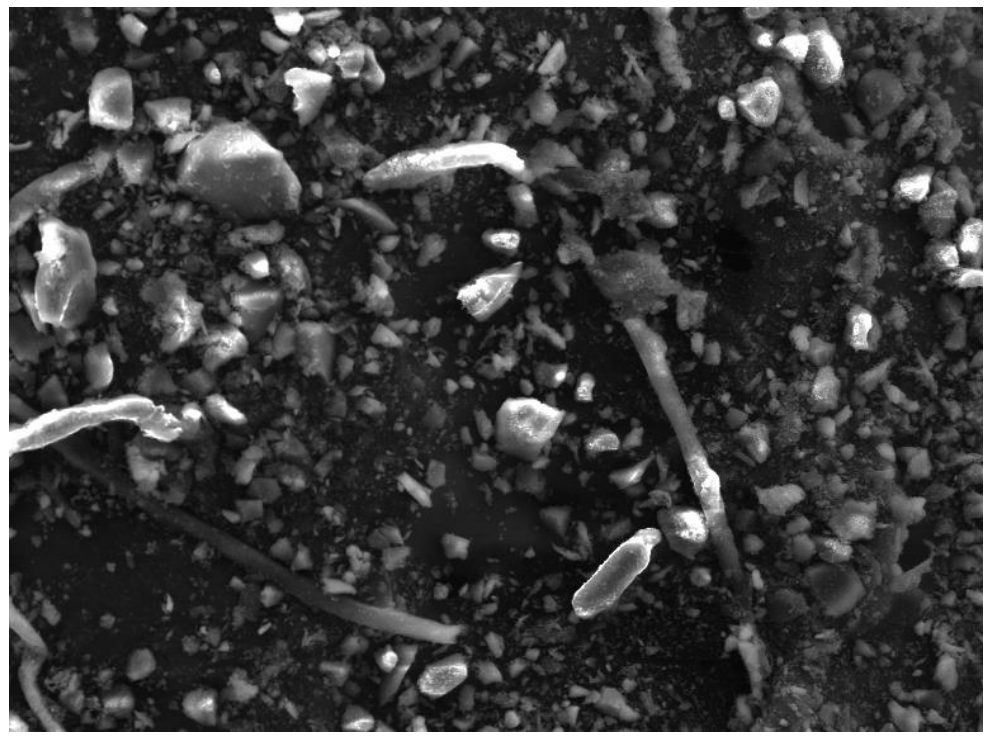

Fig 6: SEM of BS/SF/PUF/TiO2 (1:1:1:1)

The SEM images of BS, BS/SF/PUF (1:1:1) and BS/SF/PUF/TiO $2(1: 1: 1: 1)$ are shown in the figures 4, 5 and 6 respectively. All the three images show that the prepared biocomposites contain irregular morphology and rough surface. The samples contain numerous voids and pores which is essential for biological properties of the prepared composites. The images also prove the amorphous nature of the biocomposites appropriateness for cells to attach and provides higher proliferation rate.

\section{Antioxidant Activity}

Antioxidants are well-known for their health-promoting properties. They shield the body from reactive oxygen species (ROS), which cause oxidative damage to membrane lipids, proteins, and DNA. In recent years, a lot of effort has gone into researching the antioxidant activity of biosilica and its derivatives [17].

\section{Antioxidant activity}

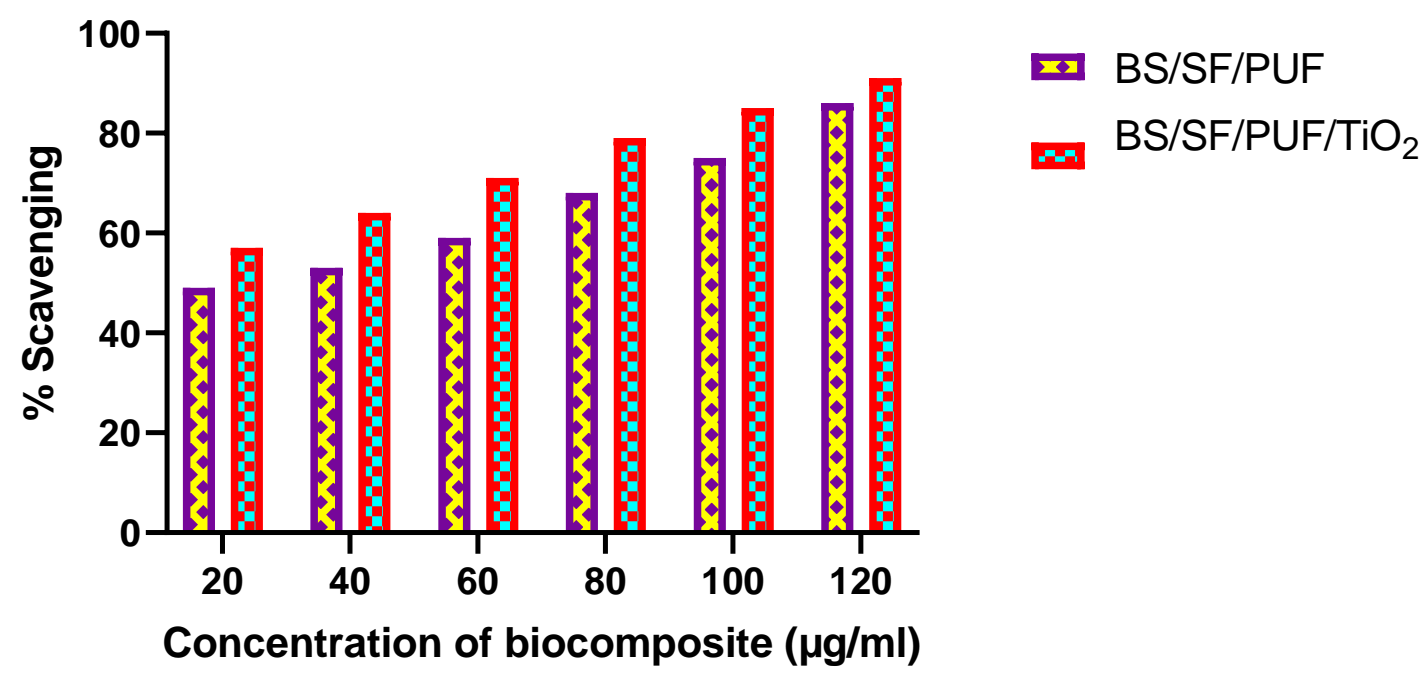

Fig. 7: Antioxidant Activity of BS/SF/PUF (1:1:1) and BS/SF/PUF/TiO2 (1:1:1:1) biocomposites 
The percentage of DPPH radical scavenging activity of BS/SF/PUF (1:1:1) and $\mathrm{BS} / \mathrm{SF} / \mathrm{PUF} / \mathrm{TiO}_{2}(1: 1: 1: 1)$ biocomposites at various concentrations is depicted in Fig. 7 . The biocomposites' antioxidant activity was tested at doses of 20,40,60, 80,100, and $120 \mu \mathrm{g} / \mathrm{ml}$. The proportion of scavenging increases as the concentration of both biocomposites increases, according to the findings. The percentage of scavenging activity in the BS/SF/PUF (1:1:1) biocomposite steadily increased from 49 percent to 86 percent. The scavenging percentage for the $\mathrm{BS} / \mathrm{SF} / \mathrm{PUF} / \mathrm{TiO}_{2}(1: 1: 1: 1)$ biocomposite increased from 57 to 91 percent. Both innovative biocomposites had good antioxidant capabilities, as per results. When the antioxidant activity of both biocomposites was compared, the biocomposite $\mathrm{BS} / \mathrm{SF} / \mathrm{PUF} / \mathrm{TiO}_{2}$ (1:1:1:1) performed better than BS/SF/PUF (1:1:1). The hydroxyl $(\mathrm{OH})$ and amino $(\mathrm{NH})$ groups in $\mathrm{BS} / \mathrm{SF} / \mathrm{PUF}$ and $\mathrm{BS} / \mathrm{SF} / \mathrm{PUF} / \mathrm{TiO}_{2}$ biocomposites are the important functional groups for antioxidant activity, but they can be difficult to dissociate due to the amorphous structure of the bicomposite with strong hydrogen bonding [18].

\section{Antimicrobial Activity}

ANTIBACTERIAL ACTIVITY

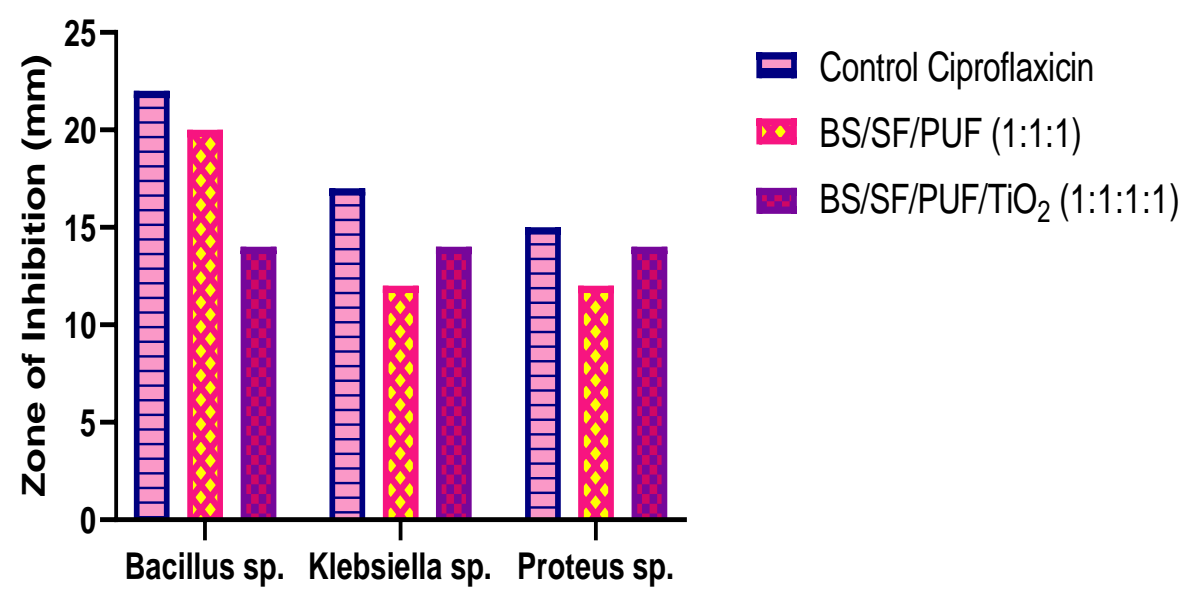

Figure 8: Antibacterial Activity of BS/SF/PUF and BS/SF/PUF/TiO 2 biocomposites

The Agar Well Diffusion method was used to evaluate the antibacterial activities of the synthesized biocomposites $\mathrm{BS} / \mathrm{SF} / \mathrm{PUF}$ and $\mathrm{BS} / \mathrm{SF} / \mathrm{PUF} / \mathrm{TiO}_{2}$ using Ciproflaxicin as the control and the outcome of the test is represented in Figure 8. From the results, it is evident that the biocomposites act well against gram-positive as well as the gram-negative bacteria. On comparing the zone of inhibition values of the biocomposites, it can be clearly seen that the BS/SF/PUF biocomposites acts well against the Bacillus sp. with the zone value of 20 $\mathrm{mm}$. On the other hand, the $\mathrm{BS} / \mathrm{SF} / \mathrm{PUF} / \mathrm{TiO}_{2}$ with the zone value of $14 \mathrm{~mm}$ against Klebsiella sp. and $14 \mathrm{~mm}$ against Proteus sp. acts better than BS/SF/PUF against the Klebsiella sp. and Proteus sp. with the zone value of $12 \mathrm{~mm}$ and $12 \mathrm{~mm}$ respectively.

After a quick shock, the prepared biocomposites could be evenly dispersed in the bacterial solution, allowing bacteria to adhere to the surface in a short period of time, indicating its antibacterial action [19,20]. The negatively charged surface of the bacterial cell is the target site of the functional groups of the prepared biocomposites. The bacteria interact with the surface of biocomposites more effectively, inhibiting the microorganism's development [21,22]. 


\section{ANTIFUNGAL ACTIVITY}

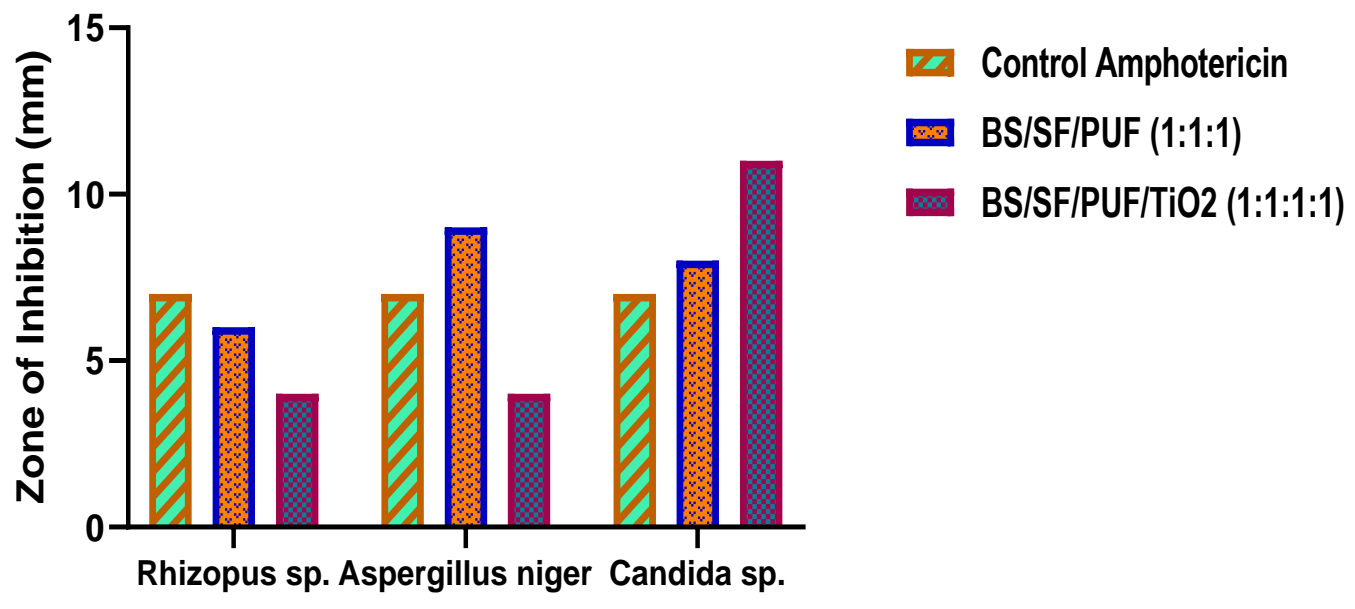

Figure 9: Antifungal Activity of BS/SF/PUF and BS/SF/PUF/TiO 2 biocomposites

The prepared biocomposites $\mathrm{BS} / \mathrm{SF} / \mathrm{PUF}$ and $\mathrm{BS} / \mathrm{SF} / \mathrm{PUF} / \mathrm{TiO}_{2}$ were tested against Rhizopus species, Aspergillus niger and Candida species, and the results are presented in figure 9. When compared to the control ampotericin, the results showed that BS/SF/PUF and $\mathrm{BS} / \mathrm{SF} / \mathrm{PUF} / \mathrm{TiO}_{2}$ was effective against Aspergillus niger and Candida $s p$. respectively than Rhizopus sp. According to the findings, the inhibition of BS/SF/PUF composite was stronger in the order Aspergillus niger > Candida species > Rhizopus species and for $\mathrm{BS} / \mathrm{SF} / \mathrm{PUF} / \mathrm{TiO}_{2}$ composite the order of activity was Candida species $>$ Aspergillus niger $=$ Rhizopus species . The antifungal activity of the biocomposites BS/SF/PUF and $\mathrm{BS} / \mathrm{SF} / \mathrm{PUF} / \mathrm{TiO}_{2}$ is enhanced by the electron donating groups. As a result, the predicted inhibitory mechanism of $\mathrm{BS} / \mathrm{SF} / \mathrm{PUF}$ and $\mathrm{BS} / \mathrm{SF} / \mathrm{PUF} / \mathrm{TiO}_{2}$ against Rhizopus species, Aspergillus niger and Candida species was expected to involve diffusion into fungal cells, followed by inhibition of DNA or RNA synthesis, and finally direct cell killing. Hence, become an effective and safe natural antifungal agent [23].

\section{Conclusion}

The goal of this study was to prepare and characterise BS/SF/PUF and $\mathrm{BS} / \mathrm{SF} / \mathrm{PUF} / \mathrm{TiO}_{2}$ biocomposite utilising FTIR and SEM studies. The specific interaction in polymer composites was revealed by FT-IR analysis, which also revealed probable interactions between the components used. Over all, the FTIR spectra of the biocomposites revealed distinct peaks for each of the components employed. Shifts in the peaks indicate chemical bonding between the polymers, indicating a strong interaction between all of the components. Antibacterial activities revealed that the biocomposites have strong antimicrobial action against pathogens. SEM tests revealed a high surface area and porous structure with superior adsorbability, which can enhance cell attachment.

\section{References}

[1] M. Sahebi, M.M. Hanafi, A. Siti Nor Akmar, M.Y. Rafii, P. Azizi, F.F. Tengoua, J. Nurul Mayzaitul Azwa, M. Shabanimofrad, Importance of Silicon and Mechanisms of Biosilica Formation in Plants, Biomed Res. Int. $2015 \quad$ (2015) 396010. https://doi.org/10.1155/2015/396010.

[2] P. Chindaprasirt, U. Rattanasak, Eco-production of silica from sugarcane bagasse ash for use as a photochromic pigment filler, Sci. Rep. 10 (2020) 9890. 
https://doi.org/10.1038/s41598-020-66885-y.

[3] A.B. Bageru, V.C. Srivastava, Biosilica preparation from abundantly available African biomass Teff (Eragrostis tef) straw ash by sol-gel method and its characterization, Biomass Convers. Biorefinery. 8 (2018) 971-978. https://doi.org/10.1007/s13399-0180335-5.

[4] W. Huang, S. Ling, C. Li, F.G. Omenetto, D.L. Kaplan, Silkworm silk-based materials and devices generated using bio-nanotechnology, Chem. Soc. Rev. 47 (2018) 64866504. https://doi.org/10.1039/C8CS00187A.

[5] C. Belbéoch, J. Lejeune, P. Vroman, F. Salaün, Silkworm and spider silk electrospinning: a review, Environ. Chem. Lett. (2021) 1-27. https://doi.org/10.1007/s10311-020-01147-x.

[6] A.J.T. Teo, A. Mishra, I. Park, Y.-J. Kim, W.-T. Park, Y.-J. Yoon, Polymeric Biomaterials for Medical Implants and Devices, ACS Biomater. Sci. Eng. 2 (2016) 454-472. https://doi.org/10.1021/acsbiomaterials.5b00429.

[7] W. Ma, J. Li, Y. Liu, X. Ren, Z.-G. Gu, Z. Xie, J. Liang, Preparation and characterization of excellent antibacterial TiO2/N-halamines nanoparticles, Colloids Surfaces A Physicochem. Eng. Asp. $506 \quad$ (2016) 284-290. https://doi.org/https://doi.org/10.1016/j.colsurfa.2016.06.055.

[8] Y. Wang, Y. Wu, H. Yang, X. Xue, Z. Liu, Doping TiO2 with boron or/and cerium elements: Effects on photocatalytic antimicrobial activity, Vacuum. 131 (2016) 58-64. https://doi.org/https://doi.org/10.1016/j.vacuum.2016.06.003.

[9] Y. Wang, W. Yu, A. Shu, J. Shi, M. Zhang, Polypropylene-Grafted Poly(hexamethylene guanidine)/Modified Polyethylene Monofilament and Its Antimicrobial Performance, Int. J. Polym. Sci. 2020 (2020) 6416230. https://doi.org/10.1155/2020/6416230.

[10] L. Arizka, H. Manimoy, L. Atmaja, Synthesis and Physical Properties Characterization of Montmorillonite-modified Carbon Nanotubes Filler, IOP Conf. Ser. Mater. Sci. Eng. 546 (2019) 42004. https://doi.org/10.1088/1757-899X/546/4/042004.

[11] J.-H. Kim, F.A. Sheikh, H.W. Ju, H.J. Park, B.M. Moon, O.J. Lee, C.H. Park, 3D silk fibroin scaffold incorporating titanium dioxide (TiO2) nanoparticle (NPs) for tissue engineering, Int. J. Biol. Macromol. $68 \quad$ (2014) 158-168. https://doi.org/https://doi.org/10.1016/j.ijbiomac.2014.04.045.

[12] Y. Ochoa Muñoz, M. Urbano, J. Paez, Síntesis de tio2, fase anatasa, por el método pechini, Rev. Latinoam. Metal. y Mater. S1 (2009) 931-937.

[13] G. Carissimi, C.M. Baronio, M.G. Montalbán, G. Villora, A. Barth, On the Secondary Structure of Silk Fibroin Nanoparticles Obtained Using Ionic Liquids: An Infrared Spectroscopy Study, Polym. . 12 (2020). https://doi.org/10.3390/polym12061294.

[14] P. Meenakshi, N. Sheik, R. Rajini, U. Venkateswarlu, C. Rose, T. Sastry, Mechanical and microstructure studies on the modification of CA film by blending with PS, Bull. Mater. Sci. 25 (2002) 25-29. https://doi.org/10.1007/BF02704590.

[15] Y. xu, K.M. Kim, M. Hanna, D. Nag, Chitosan-starch composite film: Preparation and characterization, Ind. Crops Prod. $21 \quad$ (2005) 185-192. https://doi.org/10.1016/j.indcrop.2004.03.002.

[16] Y.J. Yin, K.D. Yao, G.X. Cheng, J.B. Ma, Properties of polyelectrolyte complex films of chitosan and gelatin, Polym. Int. 48 (1999) 429-432. https://doi.org/https://doi.org/10.1002/(SICI)1097-0126(199906)48:6<429::AIDPII60>3.0.CO;2-1.

[17] G.M. Saavedra, N.E. Figueroa, L.A. Poblete, S. Cherian, C.R. Figueroa, Effects of preharvest applications of methyl jasmonate and chitosan on postharvest decay, quality and chemical attributes of Fragaria chiloensis fruit., Food Chem. 190 (2016) 448-453. https://doi.org/10.1016/j.foodchem.2015.05.107. 
[18] M. Rodríguez-Vázquez, B. Vega-Ruiz, R. Ramos-Zúñiga, D.A. Saldaña-Koppel, L.F. Quiñones-Olvera, Chitosan and Its Potential Use as a Scaffold for Tissue Engineering in Regenerative Medicine., Biomed Res. Int. 2015 (2015) 821279. https://doi.org/10.1155/2015/821279.

[19] R.M. Abdel-Rahman, A.M. Abdel-Mohsen, R. Hrdina, L. Burgert, Z. Fohlerova, D. Pavliňák, O.N. Sayed, J. Jancar, Wound dressing based on chitosan/hyaluronan/nonwoven fabrics: Preparation, characterization and medical applications., Int. J. Biol. Macromol. $89 \quad$ (2016) 725-736. https://doi.org/10.1016/j.ijbiomac.2016.04.087.

[20] R.A.-B. Sanad, H.M. Abdel-Bar, Chitosan-hyaluronic acid composite sponge scaffold enriched with Andrographolide-loaded lipid nanoparticles for enhanced wound healing., Carbohydr. Polym. 173 (2017) 441-450. https://doi.org/10.1016/j.carbpol.2017.05.098.

[21] T.T. Yuan, P.M. Jenkins, A.M. DiGeorge Foushee, A.R. Jockheck-Clark, J.M. Stahl, Electrospun Chitosan/Polyethylene Oxide Nanofibrous Scaffolds with Potential Antibacterial Wound Dressing Applications, J. Nanomater. 2016 (2016) 6231040. https://doi.org/10.1155/2016/6231040.

[22] Z. Hadisi, J. Nourmohammadi, S.M. Nassiri, The antibacterial and anti-inflammatory investigation of Lawsonia Inermis-gelatin-starch nano-fibrous dressing in burn wound., Int. J. Biol. Macromol. $107 \quad$ (2018) 2008-2019. https://doi.org/10.1016/j.ijbiomac.2017.10.061.

[23] D. Simonaitiene, I. Brink, A. Sipailiene, D. Leskauskaite, The effect of chitosan and whey proteins-chitosan films on the growth of Penicillium expansum in apples., J. Sci. Food Agric. 95 (2015) 1475-1481. https://doi.org/10.1002/jsfa.6846. 